\title{
The dynamic effects of fiscal reforms and tax competition on tax compliance and migration
}

DOI:

10.1111/roie. 12318

\section{Document Version}

Accepted author manuscript

Link to publication record in Manchester Research Explorer

\section{Citation for published version (APA):}

Lamantia, F., \& Pezzino, M. (2017). The dynamic effects of fiscal reforms and tax competition on tax compliance and migration. Review of International Economics. https://doi.org/10.1111/roie.12318

\section{Published in:}

Review of International Economics

\section{Citing this paper}

Please note that where the full-text provided on Manchester Research Explorer is the Author Accepted Manuscript or Proof version this may differ from the final Published version. If citing, it is advised that you check and use the publisher's definitive version.

\section{General rights}

Copyright and moral rights for the publications made accessible in the Research Explorer are retained by the authors and/or other copyright owners and it is a condition of accessing publications that users recognise and abide by the legal requirements associated with these rights.

\section{Takedown policy}

If you believe that this document breaches copyright please refer to the University of Manchester's Takedown Procedures [http://man.ac.uk/04Y6Bo] or contact uml.scholarlycommunications@manchester.ac.uk providing relevant details, so we can investigate your claim.

\section{OPEN ACCESS}




\title{
The dynamic effects of fiscal reforms and tax competition on tax compliance and migration
}

\author{
Fabio Lamantia* Mario Pezzino
}

July 6, 2017

\begin{abstract}
We study the dynamic effects of fiscal reforms on migration and tax evasion in an international context with two asymmetric countries. Given an initial international distribution of honest and dishonest tax payers, the tax system (e.g. tax rates and degrees of progressivity) and the salary in each country, individuals decide where to reside and how much time to spend working. The model allows us to study in a dynamic setting how the distribution of honest and dishonest earners is geographically affected by fiscal reforms (e.g. variations in tax rates) and auditing efforts (e.g. probability of auditing and fines) of different countries. We show that various dynamic long term scenarios can be generated. The particular convergence of the model depends crucially on the initial geographic distribution of dishonest agents. This implies that tax reforms that have been successful in reducing tax evasion in one country may produce very different results in others, if initial conditions are significantly different. Chaotic cyclical behavior may also arise if individual propensity to migrate is sufficiently high.
\end{abstract}

Keywords: migration; tax evasion; progressive vs. flat tax; evolutionary dynamics.

JEL codes: H26; H31; F22.

\section{Introduction}

All around the world the wealth of economic agents is taxed by local and central governments to finance expenditure in services to the population. Fiscal policy

*Lamantia: Department of Economics, Statistics and Finance (DESF), University of Calabria, Via P. Bucci 1/C, Rende (CS), Italy. E-mail: fabio.lamantia@unical.it. Pezzino: School of Social Sciences, University of Manchester, Manchester, UK. Email:Mario.Pezzino@manchester.ac.uk. Lamantia is also affiliated to the University of Manchester, UK. We would like to thank Spiros Bougheas, Pasquale Commendatore, Ingrid Kubin, the participants of the GeComplexity Conference in Crete, May 26-27, 2016, and the anonymous reviewers of the paper for helpful comments and suggestions. Financial support under EU COST Action IS1104 "The EU in the new economic complex geography: models, tools and policy evaluation." is gratefully acknowledged. 
makers, in general, have to face the fact that taxes may influence individuals' economic behavior and, in many situations, they are a very important factor affecting the financial decisions of households and firms.

A particularly important issue connected to taxation is the possibility that some individuals may decide to report smaller earning or not pay taxes at all; in other words, they may decide to engage in forms of tax evasion. Tax evasion is a common and widespread problem that fiscal policy makers face around the world. The traditional view in the economic literature originates from the economics of crime (Becker (1968)) and is based on the idea that no individual, if allowed, would want to pay taxes. Indeed tax evasion has often been described as a gamble. ${ }^{1}$

Recently, the economic literature has also started considering the fact that some individuals in the society may be inherently honest and, to some extent, may also obtain a positive utility from paying taxes. Due to the existence of some form of intrinsic motivation among tax payers, ${ }^{2}$ some individuals may believe that paying taxes is a citizenship duty and a way to contribute to society's welfare. Of course, individuals' tax morale, i.e. their propensity to be intrinsically motivated toward honestly paying taxes, may be significantly affected by the way they see the actions of their governments. Indeed, in those countries in which governments are considered particularly corrupted or inefficient, the intrinsic motivation of individuals to pay taxes may be very low. ${ }^{3}$

Importantly, the inclination of taxpayers to honestly report their earnings may also be affected by various aspects of a tax system. For instance, a tax system that includes strict auditing and harsh fines may be seen as greedy and oppressive by the average taxpayer.

In an international context, fiscal policy makers have to consider the possibility that economic agents may rationally decide to reside in countries in which the tax system has features that match their preferences. Indeed, the economic literature has shown significant interest in understanding the relationship between tax competition and migration. Such relationship is a two-way one. On one hand, differences in national tax systems may induce migration of economic agents; on the other, changes in other factors that affect migration (such as costs of migration or skill differentials) may influence, in turn, the way optimal taxes should be defined. The relationship between tax competition and migration has been studied in various papers - Mirrlees (1971) and (1982), Borjas (1999), Razin et al. (2002), Bucovetsky (2003), Simula and Trannoy (2010) looking for forms of optimal taxation when economic agents are allowed to migrate. Our paper contributes to the literature studying another important and,

\footnotetext{
${ }^{1}$ See, for example, Allingham and Sandmo (1972), Yitzhaki (1974), Slemrond and Yitzhaki (2002). See Freire-Serén and Panadés (2013) for a review of the literature.

${ }^{2}$ See for example Besley and Ghatak (2005) and Bénabou and Tirole (2006).

${ }^{3}$ Recent psychology literature provides a very useful framework, the so called Slippery Slope model, to study the formation of tax morale and the way it influences tax payers' behavior (see Gangl et al. (2015)). Economics literature, at the same time, has been testing the effects of tax morale both empirically and in the lab (see for example Frey (2003), Alm et al. (2010), Cumming at al. (2009) and, more recently, Castro and Scartascini (2015) and Doerrenberg (2015)). See also Luttmer and Singhal (2014).
} 
to our knowledge, scarcely explored relationship: the evolutionary connection between tax/auditing systems, tax evasion and migration. In other words, we study in a dynamic setting the way different taxation and auditing systems may affect the migration decisions of individuals who intend to commit tax evasion. Specifically, we consider a two-country framework and assume that each country employs a different tax system (i.e. different rates and different degrees of progressivity). ${ }^{4}$ In addition, we assume that economic agents can decide how much effort to invest in economic activities and whether to migrate to a country with a more favorable tax system. An evolutionary model, in which the fraction of dishonest payers residing in each country is endogenized and updated according to expected utilities, provides the dynamics that we are going to discuss.

We show that various dynamic long term scenarios can be generated, including equilibria in which all dishonest individuals converge to one of the countries as well as equilibria where dishonest individuals are distributed in both countries. In addition, the stability of the equilibria may be affected by overshooting; in particular, instability (chaotic cyclical behavior) may arise if individuals' propensity to migrate is sufficiently high. The particular convergence of the evolutionary process often depends crucially on the initial geographic distribution of dishonest agents. This provides an important caveat to fiscal policymakers who may be considering to adopt fiscal reforms that have been successful in other countries. The model shows that tax reforms that have been successful in reducing tax evasion in one country may produce very different results in another, if initial levels of tax evasion are significantly different. Finally, we show that the particular evolutionary trajectory of tax evasion and migration that a country can experience critically depends on the level of progressivity of a tax system. In particular, we show that the progressivity of tax regime influences individuals' choices in terms of effort and migration and this, in turn, has consequences on the ability of a country to generate tax revenues. Our analysis shows that a tendency to a flat rate system may have positive effects on the tax revenues of a country.

The remainder of the paper is organized as follows. Section 2 describes the basic model. Section 3 introduces the evolutionary dynamics. Section 4 discusses the results and provides examples. Section 5 concludes.

\section{The Model}

Assume there are two countries, say country 1 and country 2. Country 1 has a progressive tax system with two rates, $t_{L}$ and $t_{H}, 0<t_{L}<t_{H}<1$. Thus, in country 1 , if a worker earns more than a certain exogenous income level $I$, then she pays rate $t_{H}$ on the earnings exceeding $I$. The rate $t_{L}$ applies, instead, for earnings less than $I$. Country 2 has a flat tax system with tax rate $0<t_{F}<1$.

\footnotetext{
${ }^{4}$ Various countries have been recently introducing flat rate tax system. A particularly notewhorty example is provided by Russia. In 2001 a progressive tax system with rates $12 \%$, $20 \%$ and $30 \%$ was replaced in Russia by a flat tax rate of $13 \%$. Interestingly, Gorodnichenko et al. (2009) empirically showed that the reform produced a reduction in tax evasion.
} 
Agents are homogeneous with (pre-tax) utility given by

$$
U_{i}=e w_{i}-\gamma \frac{e^{2}}{2}
$$

where $e$ is effort, $w_{i}$ is the wage in country $i$ and $\gamma \frac{e^{2}}{2}$ represents the cost of effort with parameter $\gamma$ measuring effort inefficiency. Notice that in country 1 , the cut-off level of taxable income $I$ can also be expressed in terms of a threshold level of effort: $I=\widetilde{e} w_{1}$.

Let us assume that there are two types of individuals, i.e. cheaters (or dishonest agents) and honest tax payers. Cheaters are assumed to report always a level of income equal to zero and, if not audited, their utility is given by (1). If audited, cheaters pay the due amount plus a country-specific fine, e $m_{i}$, which is proportional to the effort (and therefore the income earned).

Let us assume that honest taxpayers always declare the correct amount. We can now summarize the utilities of agents in the two countries in the following tables:

Low income - Country 1

\begin{tabular}{|l|l|l|}
\hline$e<\widetilde{e}$ & Compliance & Evasion \\
\hline Audit & $e w_{1}\left(1-t_{L}\right)-\gamma \frac{e^{2}}{2}$ & $e w_{1}\left(1-t_{L}\right)-\gamma \frac{e^{2}}{2}-e m_{1}$ \\
\hline No audit & $e w_{1}\left(1-t_{L}\right)-\gamma \frac{e^{2}}{2}$ & $e w_{1}-\gamma \frac{e^{2}}{2}$ \\
\hline
\end{tabular}

High Income - Country 1

\begin{tabular}{|l|l|l|}
\hline$e \geq \widetilde{e}$ & Compliance & Evasion \\
\hline Audit & $e w_{1}\left(1-t_{H}\right)+\widetilde{e} w_{1}\left(t_{H}-t_{L}\right)-\gamma \frac{e^{2}}{2}$ & $e w_{1}\left(1-t_{H}\right)+\widetilde{e} w_{1}\left(t_{H}-t_{L}\right)-\gamma \frac{e^{2}}{2}-e m_{1}$ \\
\hline No audit & $e w_{1}\left(1-t_{H}\right)+\widetilde{e} w_{1}\left(t_{H}-t_{L}\right)-\gamma \frac{e^{2}}{2}$ & $e w_{1}-\gamma \frac{e^{2}}{2}$ \\
\hline
\end{tabular}

\section{Country 2}

\begin{tabular}{|l|l|l|}
\hline & Compliance & Evasion \\
\hline Audit & $e w_{2}\left(1-t_{F}\right)-\gamma \frac{e^{2}}{2}$ & $e w_{2}\left(1-t_{F}\right)-\gamma \frac{e^{2}}{2}-e m_{2}$ \\
\hline No audit & $e w_{2}\left(1-t_{F}\right)-\gamma \frac{e^{2}}{2}$ & $e w_{2}-\gamma \frac{e^{2}}{2}$ \\
\hline
\end{tabular}

With probability $p_{i} \in[0,1]$ an agent located in country $i$ will be audited and we assume that the auditor identifies correctly the taxable income.

It follows that the expected utility of a dishonest agent in country 1 is:

$$
\mathbb{E}\left[U_{1}(e)\right]=\left\{\begin{aligned}
\mathbb{E}\left[U_{1}^{L}(e)\right]= & p_{1}\left[e w_{1}\left(1-t_{L}\right)-\gamma \frac{e^{2}}{2}-e m_{1}\right]+ \\
& +\left(1-p_{1}\right)\left(e w_{1}-\gamma \frac{e^{2}}{2}\right) \quad \text { if } e \leq \widetilde{e} \\
\mathbb{E}\left[U_{1}^{H}(e)\right]= & p_{1}\left[e w_{1}\left(1-t_{H}\right)+\widetilde{e} w_{1}\left(t_{H}-t_{L}\right)-\gamma \frac{e^{2}}{2}-e m_{1}\right]+ \\
& +\left(1-p_{1}\right)\left(e w_{1}-\gamma \frac{e^{2}}{2}\right) \quad \text { if } e>\widetilde{e}
\end{aligned}\right.
$$


Note that the expected utility in country 1 as a function of the effort $e$ is continuous, but has a kink point at the threshold $\widetilde{e}$, due to the progressivity of the tax system. The (certain) utility of an honest agent in country 1 is:

$$
\bar{U}_{1}(e)= \begin{cases}e w_{1}\left(1-t_{L}\right)-\gamma \frac{e^{2}}{2} & \text { if } e<\widetilde{e} \\ e w_{1}\left(1-t_{H}\right)+\widetilde{e} w_{1}\left(t_{H}-t_{L}\right)-\gamma \frac{e^{2}}{2} & \text { if } e \geq \widetilde{e}\end{cases}
$$

The expected utility of a dishonest agent in country 2 is:

$$
\mathbb{E}\left[U_{2}(e)\right]=p_{2}\left[e w_{2}\left(1-t_{F}\right)-\gamma \frac{e^{2}}{2}-e m_{2}\right]+\left(1-p_{2}\right)\left(e w_{2}-\gamma \frac{e^{2}}{2}\right) .
$$

Cheaters and honest taxpayers decide their effort levels by solving an expected utility maximization problem. A dishonest agent in country 2 , where a flat tax is imposed, will exert the level of effort that maximizes (2), which is:

$$
e_{2}^{*}=\frac{1}{\gamma}\left[w_{2}\left(1-t_{F} p_{2}\right)-p_{2} m_{2}\right]
$$

thus obtaining utility

$$
\mathbb{E}\left[U_{2}\left(e_{2}^{*}\right)\right]:=\mathbb{E}\left[U_{2}^{*}\right]=\frac{1}{2 \gamma}\left[w_{2}\left(1-t_{F} p_{2}\right)-p_{2} m_{2}\right]^{2}
$$

Discarding the possibility of negative levels of effort, i.e. assuming that

$$
0 \leq m_{2} \leq \frac{w_{2}}{p_{2}}-w_{2} t_{F}
$$

simple comparative statics analysis shows that effort $e_{2}^{*}$ and corresponding expected utility $\mathbb{E}\left[U_{2}^{*}\right]$ decrease with $\gamma, p_{2}, t_{F}$ and $m_{2}$, and increase with $w_{2}$. It is not particularly surprising that the effort of a dishonest agent decreases if the auditing system becomes stricter (i.e. $m_{2}$ and $p_{2}$ increase) or the tax burden increases (i.e. higher $t_{F}$ ); an increase in $\gamma$ also increases the costs of effort and, therefore, reduces its provision. Clearly, effort and utility of an honest agent in country 2 , denoted by $e_{2}^{+}$, are obtained by setting $p_{2}=1$ and $m_{2}=0$ in (3) and (4) respectively.

An analogous computation holds for calculating the optimal effort of a dishonest low income agent in country 1 , with

$$
e_{L}^{*}=\frac{1}{\gamma}\left[w_{1}\left(1-t_{L} p_{1}\right)-p_{1} m_{1}\right]
$$

and

$$
\mathbb{E}\left[U_{1}^{L}\left(e_{L}^{*}\right)\right]:=\mathbb{E}\left[U_{1}^{L^{*}}\right]=\frac{1}{2 \gamma}\left[w_{1}\left(1-t_{L} p_{1}\right)-p_{1} m_{1}\right]^{2}
$$

If a cheater in country 1 exerts an effort beyond the threshold $I=\widetilde{e} w_{1}$, then the effort level that maximizes $\mathbb{E}\left(U_{1}^{H}\right)$ is given by

$$
e_{H}^{*}=\frac{1}{\gamma}\left[w_{1}\left(1-t_{H} p_{1}\right)-p_{1} m_{1}\right]
$$


with expected utility

$$
\mathbb{E}\left[U_{1}^{H}\left(e_{H}^{*}\right)\right]:=\mathbb{E}\left[U_{1}^{H^{*}}\right]=\frac{1}{2 \gamma}\left[w_{1}\left(1-t_{H} p_{1}\right)-p_{1} m_{1}\right]^{2}+\widetilde{e} p_{1} w_{1}\left(t_{H}-t_{L}\right)
$$

Finally, if the cheater exerts an effort equal to the threshold $\widetilde{e}$, his utility is given by

$$
\mathbb{E}\left[U_{1}(\widetilde{e})\right]:=\mathbb{E}\left[U_{1}^{M^{*}}\right]=w_{1} \widetilde{e}-\widetilde{e} p_{1}\left(m_{1}+t_{L} w_{1}\right)-\gamma \frac{\widetilde{e}^{2}}{2}
$$

Notice that relationship $e_{H}^{*}<e_{L}^{*}$ always holds. Again, assuming nonnegative effort in country 1 , changes in parameters have effects on $e_{L}^{*}, e_{H}^{*}$, $\mathbb{E}\left[U_{1}^{L^{*}}\right]$ similar to what we have described above. In other words, an increase in the cost of effort, the probability of auditing, tax rates and fines have a negative effect on effort and expected utilities of dishonest agents. Increases in $w_{1}$ have a positive effect instead.

The way $\mathbb{E}\left[U_{1}^{H^{*}}\right]$ is affected by parameters, nonetheless, is less obvious. Still, increases in $\gamma$ and $m_{1}$ have a negative effect on $\mathbb{E}\left[U_{1}^{H^{*}}\right]$, while $w_{1}$ increases expected utility. However, now the effect that $p_{1}$ and $t_{H}$ have on the expected utility of high-effort dishonest agents may be ambiguous. In addition, an increase in $t_{L}$ has a negative effect on the expected utility (it decreases the tax relief provided by tax progressivity in the event tax evasion is detected), but not on effort. Similarly, notice that an increase in the threshold $\widetilde{e}$ has a positive effect on $\mathbb{E}\left[U_{1}^{H^{*}}\right]$ and $\mathbb{E}\left[U_{1}^{M^{*}}\right]$.

In what follows, we are interested in cases in which probabilities $p_{1}$ and $p_{2}$ are not exogenously given, but are dynamically updated according to the share of cheaters in the two countries. Therefore, we will assume from now on the following restrictions on parameters, which guarantee that optimal efforts are non-negative for any level of probabilities $p_{1}$ and $p_{2}:^{5}$

$$
m_{1} \in\left[0, w_{1}\left(1-t_{H}\right)\right]
$$

and

$$
m_{2} \in\left[0, w_{2}\left(1-t_{F}\right)\right]
$$

Working out the conditions for maximizing cheater's expected utility in country $1, \mathbb{E}\left[U_{1}(e)\right]$, his optimal effort, denoted by $e_{1}^{*}$, is

$$
e_{1}^{*}=\left\{\begin{array}{l}
e_{H}^{*} \text { if } 0<\widetilde{e} \leq e_{H}^{*} \\
\widetilde{e} \text { if } e_{H}^{*}<\widetilde{e}<e_{L}^{*} \\
e_{L}^{*} \text { if } \widetilde{e} \geq e_{L}^{*}
\end{array}\right.
$$

\footnotetext{
${ }^{5}$ It is easy to show that assumptions (11) and (12) guarantee nonnegative optimal efforts $(6),(8)$ and (3). For instance, consider (5) and notice that $\frac{w_{2}}{p_{2}}-w_{2} t_{F}$ is strictly decreasing in $p_{2}$, so that the minimum value of $\frac{w_{2}}{p_{2}}-w_{2} t_{F}$ is at $p_{2}=1$, thus leading to (12). For (11), a similar reasoning applies.
} 
The utility at the optimal effort level for a cheater in country 1 is then

$$
\mathbb{E}\left[U_{1}^{*}\right]=\left\{\begin{array}{l}
\mathbb{E}\left[U_{1}^{H^{*}}\right] \text { if } 0<\widetilde{e} \leq e_{H}^{*} \\
\mathbb{E}\left[U_{1}^{M^{*}}\right] \text { if } e_{H}^{*}<\widetilde{e}<e_{L}^{*} \\
\mathbb{E}\left[U_{1}^{L^{*}}\right] \text { if } \widetilde{e} \geq e_{L}^{*}
\end{array}\right.
$$

where $\mathbb{E}\left[U_{1}^{H^{*}}\right], \mathbb{E}\left[U_{1}^{M^{*}}\right]$ and $\mathbb{E}\left[U_{1}^{L^{*}}\right]$ are given, respectively, in (9), (10) and (7). An analogous calculation holds for the optimal effort $e_{1}^{+}$and maximized utility for a honest agent in country 1 by setting $m_{1}=0$ and $p_{1}=1$ in (13) and (14) respectively.

Next we address the following question. Given an initial distribution of cheaters in the two countries and given that cheaters may find profitable to migrate in the country where their expected utility is greatest, should we expect migration between the two countries to be influenced by the different tax systems?

To answer this question, we specify an evolutionary setting with migration of dishonest taxpayers between countries, based on expected utility comparison between countries.

\section{$3 \quad$ Evolutionary setting}

In this section, we endogenize $r$, the fraction of cheaters deciding to reside in country 1 , in order to study the migration of dishonest agents between the two countries.

We disregard the possibility of a change in the attitude of the agents from honest to cheater and vice-versa. In other words, we are assuming that each individual is innately either honest or dishonest (see Lamantia and Pezzino (2016) for a related example where individual behavior could indeed change). Of course, the proportion of honest/dishonest agents residing in a country can change in time because of migration. We disregard, however, any possible migration of honest taxpayers. This assumption clearly simplifies the analysis and it is justified by the fact that inherently honest tax payers tend to have significant tax morale and, therefore, a closer connection with the country where they reside. In other words, it is reasonable to assume that honest tax payers may find more difficult to migrate to a different country because of tax-related considerations compared to intrinsically dishonest agents.

Let us focus, therefore, on dishonest agents and consider the average payoff obtained by each of them in the two countries. It is reasonable to assume that at time $t$ the probability of observing dishonest behavior in a country is approximated by the fraction $r$ of dishonest agents in that country. Then, this probability is dynamically updated according to the gain in expected utilities produced by migration. The specific dynamics of the probability of being dishonest is modeled by the word of mouth evolutionary model, see Ellison and Fudenberg (1995) and Dawid (1999) ${ }^{6}$

\footnotetext{
${ }^{6} \mathrm{~A}$ similar modeling structure as the one here proposed has been employed in evolutionary
} 
To be more precise, suppose that at each (discrete) time period two dishonest agents meet and compare their utilities. Agents are homogeneous and set their effort to maximize expected utility. Thus, if both agents reside in the same country, they obtain the same utility and there is no awareness of the advantages of migration. However, if a dishonest taxpayer living in country 1 meets a dishonest taxpayer of country 2, they could compare their utility and reconsider the country to live in. The higher the difference in expected utilities of being dishonest in the two countries is, the more likely the dishonest agents will migrate to the country where expected utility is higher. Define as $G$ the difference of expected utilities:

$$
G=\mathbb{E}\left[U_{1}^{*}\right]-\mathbb{E}\left[U_{2}^{*}\right]
$$

Consider the probability $\Phi$ to migrate from country 2 to country 1 given that $G \geq 0$, and denote it by $\Phi(G)$ :

$$
\Phi(G)=\mathbb{P}(2 \rightarrow 1 \mid G \geq 0)
$$

$\Phi$, being a probability distribution function, is non-decreasing in its argument $G$ with

$$
\begin{aligned}
& \lim _{G \rightarrow-\infty} \Phi(G)=0 \\
& \lim _{G \rightarrow+\infty} \Phi(G)=1
\end{aligned}
$$

From now on, we denote by $r$ the fraction of dishonest tax payers in country 1. All in all, the probability $p_{2 \rightarrow 1}$ that a dishonest migrates from country 2 to country 1 is given by the probability that a dishonest of country 2 meets a dishonest of country 1 , which is $r$, times the probability $\Phi$ to change behavior, namely

$$
p_{2 \rightarrow 1}=r \Phi(G)
$$

from which it follows that the probability to remain in country 2 is $p_{2 \rightarrow 2}=$ $1-p_{2 \rightarrow 1}$. Analogously, a dishonest agent of country 1 migrate to country 2 with probability given by the probability that (s)he meets a dishonest of country 2, which is $(1-r)$, times the probability $\Psi$ that a dishonest of country 1 migrates to country 2 given the difference in (15). Assuming that $\Psi(-x)=1-\Phi(x)$, the overall probability that a dishonest of country 1 migrates to country 2 is

$$
p_{1 \rightarrow 2}=(1-r)[1-\Phi(G)]
$$

with an obvious meaning of the notation. Finally, it is $p_{1 \rightarrow 1}=1-p_{1 \rightarrow 2}$.

Suppose that the probability that an agent is sampling another agent from the other country is linearly increasing with the number of dishonest agents in that other country and that a large number of sampling from the population

oligopolies to investigate competition where players have different information sets or different objective functions, see Bischi et al. (2015), Cerboni Baiardi et al. (2015), Droste et al. (2002), Kopel et al. (2014), De Giovanni and Lamantia (2016). 
is taken. This way, the average utility difference of the two behaviors is well approximated by the difference of expected utilities in (15). Denote by $r_{t}$ the fraction of dishonest tax payers in country 1 , where $t$ emphasizes its dependence on time. Following Dawid (1999), the dynamics of the probability $r_{t}$ can be written as follows:

$$
\begin{aligned}
r_{t+1} & =r_{t}+\underbrace{\left(1-r_{t}\right) p_{2 \rightarrow 1}}_{\text {inflow share of migration from country } 2 \text { to } 1}-\underbrace{r_{t} p_{1 \rightarrow 2}}_{\text {outflow share of migration from }} \\
& =r_{t}+r_{t}\left(1-r_{t}\right) \Phi(G)-r_{t}\left(1-r_{t}\right)[1-\Phi(G)]
\end{aligned}
$$

which can be rewritten as the unidimensional map

$$
r_{t+1}=r_{t}\left[1+\left(1-r_{t}\right) M(G)\right]
$$

where

$$
M(G)=2 \Phi(G)-1 .
$$

is referred to as the "switching" function, see Bischi et al. (2003a,b).

Equation (16) can be interpreted as a balance equation, saying that in country 1 the fraction of dishonest agents at time $t+1, r_{t+1}$, is increased by the expected fraction of dishonest agents that decide to migrate from country 2 to country $1,\left(1-r_{t}\right) p_{2 \rightarrow 1}$, and decreased by the expected fraction of agents that decide to migrate from country 1 to country $2, r_{t} p_{1 \rightarrow 2}$.

$M$ inherits from $\Phi$ the following properties:

$$
\begin{aligned}
& \lim _{G \rightarrow-\infty} M(G)=-1 \\
& \lim _{G \rightarrow+\infty} M(G)=1
\end{aligned}
$$

Moreover, being $\Phi$ a distribution function, by the properties of the corresponding density (unimodality and symmetry), we can also assume that:

1. $M(0)=0$;

2. $M$ is odd (symmetric with respect to 0 );

3. $M$ is increasing;

4. $M$ is convex in $(-\infty, 0)$ and concave in $(0,+\infty)$;

5. $M$ is differentiable at least in $y=0 .^{7}$

Map (17) has the following important property:

Monotonicity: For a given $r_{t} \in(0,1)$ it is $r_{t+1}>r_{t}[<]$ if and only if $M(G)>0[<0]$.

By monotonicity of $M($.$) , the sign of M($.$) coincides with the sign of G$, so that an increment (decrement) in the share $r$ occurs if and only if $G>0[<0]$. By this property, we can say that the dynamical system (17) is a particular example of monotone selection dynamics, see Cressman (2003) and Weibull (1995) for details.

\footnotetext{
${ }^{7}$ A possible specification for $M(G)$ is given below.
} 


\section{Detection probabilities}

In this Section, let us assume that in each country detection rates depend on the distribution of cheaters in the two countries; that is, probabilities to be audited in the two countries $p_{1}$ and $p_{2}$ depend on the distribution of cheaters $r$. In particular, we are assuming that in both countries auditing efforts tend to increase with the degree of tax evasion in that country.

Since $p_{1}=p_{1}(r)$ and $p_{2}=p_{2}(r)$, we can rewrite (15) as

$$
G(r)=\mathbb{E}\left[U_{1}^{*}(r)\right]-\mathbb{E}\left[U_{2}^{*}(r)\right]
$$

so that word of mouth dynamics (17) becomes

$$
r_{t+1}=F\left(r_{t}\right)=r_{t}\left[1+\left(1-r_{t}\right) M\left(G\left(r_{t}\right)\right)\right]
$$

and the interval $[0,1]$ is forward invariant so that $F([0,1]) \subset[0,1]$. Proposition 1 characterizes the stability of an equilibrium for the map (20).

Proposition 1 Consider the Word of Mouth Map (20) where function $G$ is defined in (19) with $\mathbb{E}\left[U_{1}^{*}(r)\right]$ and $\mathbb{E}\left[U_{2}^{*}(r)\right]$, respectively, in (14) and (4). Let $r^{*} \in(0,1)$ be a root of equation $G\left(r^{*}\right)=0$. Then:

- $r^{*}$ is a locally asymptotically stable fixed point for (20) iff the following non-overshooting condition holds:

$$
G^{\prime}\left(r^{*}\right) \in(\theta, 0)
$$

where $\theta=\frac{-2}{r^{*}\left(1-r^{*}\right) M^{\prime}\left(G\left(r^{*}\right)\right)} ; r^{*}$ looses stability through a flip bifurcation at $G^{\prime}\left(r^{*}\right)=\theta$.

- $r^{*}$ is an unstable fixed point for (20) iff $G^{\prime}\left(r^{*}\right) \in(-\infty, \theta) \cup(0,+\infty)$.

Proof: It follows from linearization of (20) around equilibrium, see Lamantia and Pezzino (2016) or De Giovanni and Lamantia (2016) for details.

Corner points $r^{0}=0$ and $r^{1}=1$ are also possible equilibria of (20). However, here the share of cheaters in the two countries plays a crucial role in determining the expected utilities through the detection probabilities. The study of local stability for equilibrium points $r^{*} \in(0,1)$ of the map (20), where expected utilities in the two countries are equal, i.e. $G\left(r^{*}\right)=0$, can be ascertained by considering the slope of the function $M($.$) in (18). In particular, an equilibrium$ $r^{*}$ such that $G^{\prime}\left(r^{*}\right)>0$ is always unstable for (20), whereas when $G^{\prime}\left(r^{*}\right)<0$, $r^{*}$ is stable provided that no overshooting around the equilibrium takes place, as specified by condition (21).

To provide a simple application, let us assume from now on that detection probabilities in each country are equal to the share of cheaters in that country, 
i.e. $p_{1}(r)=r$ and $p_{2}(r)=1-r .^{8}$ By employing (14), the difference in cheaters' expected utilities for the two countries (19) becomes

$G(r)=\left\{\begin{array}{l}G_{H}(r)=\widetilde{e} r w_{1}\left(t_{H}-t_{L}\right)+\frac{\left(m_{1} r-w_{1}\left(1-r t_{H}\right)\right)^{2}-\left(m_{2}(1-r)-w_{2}\left(1-(1-r) t_{F}\right)\right)^{2}}{2 \gamma} \text { if } 0 \leq r \leq \bar{r} \\ G_{M}(r)=\widetilde{e}\left(w_{1}-r\left(m_{1}+t_{L} w_{1}\right)-\frac{\widetilde{e}^{2} \gamma}{2}-\frac{\left(m_{2}(r-1)+w_{2}\left((r-1) t_{F}+1\right)\right)^{2}}{2 \gamma} \text { if } \bar{r}<r<\overline{\bar{r}}\right. \\ G_{L}(r)=\frac{\left(m_{1} r-w_{1}\left(1-r t_{L}\right)\right)^{2}-\left(m_{2}(r-1)+w_{2}\left(1-(1-r) t_{F}\right)\right)^{2}}{2 \gamma} \text { if } \overline{\bar{r}} \leq r \leq 1\end{array}\right.$

where

$$
\bar{r}=\frac{w_{1}-\widetilde{e} \gamma}{m_{1}+t_{H} w_{1}} \text { and } \overline{\bar{r}}=\frac{w_{1}-\widetilde{e} \gamma}{m_{1}+t_{L} w_{1}}
$$

with $\bar{r}<\overline{\bar{r}}$. Notice that $G(r)$ in (22) is continuous so that map (20) is piecewisesmooth. ${ }^{9}$

Depending on the threshold effort level $\widetilde{e}$, the following cases arise: ${ }^{10}$

1. $0<\widetilde{e} \leq \frac{w_{1}\left(1-t_{H}\right)-m_{1}}{\gamma}$. Being $\bar{r} \geq 1$, in $(22)$ it is $G(r)=G_{H}(r)$. This case describes the situation in which the effort threshold is so low that all dishonest agents residing in country 1 will choose a high level of effort.

2. $\frac{w_{1}\left(1-t_{H}\right)-m_{1}}{\gamma}<\widetilde{e} \leq \frac{w_{1}\left(1-t_{L}\right)-m_{1}}{\gamma}$. Being $0<\bar{r}<1$ and $\overline{\bar{r}} \geq 1$, in the definition of $G(r)$ in (22) only the branches $G_{M}(r)$ and $G_{H}(r)$ are employed. This case describes the situation in which the effort threshold has increased to the point where, for some values of $r$, dishonest agents residing in country 1 will consider applying a level of effort equal to $\widetilde{e}$.

3. $\frac{w_{1}\left(1-t_{L}\right)-m_{1}}{\gamma}<\widetilde{e}<\frac{w_{1}}{\gamma}$. Being $0<\bar{r}<1$ and $0<\overline{\bar{r}}<1$, all the three branches in (22), $G_{L}(r), G_{M}(r)$ and $G_{H}(r)$, are employed. This case describes the situation in which the effort threshold has further increased to the point where, depending of the specific values of $r$, dishonest agents residing in country 1 will consider applying a level of effort equal to $\widetilde{e}, e_{H}^{*}$, $e_{L}^{*}$.

4. $\widetilde{e} \geq \frac{w_{1}}{\gamma}$. Being $\overline{\bar{r}} \leq 0$, in (22) it is $G(r)=G_{L}(r)$. This case describes the situation in which the effort threshold is so high that dishonest agents residing in country 1 will only apply a level of effort equal to $e_{L}^{*}$.

Observe that cases 1 and 4 are easier to analyze, but less interesting for our purposes: even if in principle in country 1 two tax rates are operative, cheaters choose the same level of effort (high or low in cases 1 and 4 respectively) for any underlying distribution of cheaters in the two countries. Thus, in country 1 essentially only one tax rate applies to cheaters, which is $t_{H}$ or $t_{L}$ respectively.

\footnotetext{
${ }^{8}$ Similar results are obtained when detection probabilities are linear in $r$ with $p_{1}$ increasing in $r$ and $p_{2}$ decreasing in $r$.

${ }^{9}$ See Bischi and Lamantia (2012), Cellini and Lamantia (2015), Commendatore et al. (2015) and Tramontana et al. (2010), for applications of piecewise-smooth maps in economics.

${ }^{10} \mathrm{By}$ using the assumption on nonnegative efforts, it is possible to show that the other cases are ruled out; in other words, it is not possible that in $(22)$ only the branch $G_{M}(r)$ or only the branches $G_{M}(r)$ and $G_{L}(r)$ are used.
} 
Under case 1 , where $0<\widetilde{e}<\frac{w_{1}\left(1-t_{H}\right)}{\gamma}$, it is $G(r)=G_{H}(r)$ : cheaters migrate between the two countries, but in country 1 all cheaters exert high effort, regardless of the prevailing share $r$. Thus in this case, the threshold level $\widetilde{e}$ is so low that cheaters always find profitable to exert an effort above that level, even if it could result in paying the higher tax rate if audited.

When the level of salaries and the amount of punishment are equal in the two countries $\left(w_{1}=w_{2}\right.$ and $\left.m_{1}=m_{2}\right), G_{H}(r)$ is strictly decreasing in $r \in[0,1]$ with $G_{H}(1)<0<G_{H}(0)$ so that, by continuity, exactly one equilibrium $r_{H}^{*}$, exists, which can be calculated by finding a root $r_{H}^{*}$ that solves the second degree equation $G_{H}\left(r_{H}^{*}\right)=0$ in $(22)$ and such that $0<\widetilde{e} \leq \frac{w_{1}\left(1-t_{H}\right)-m_{1}}{\gamma}$. Notice that $r_{H}^{*}$ depends on the threshold level of effort $\widetilde{e}$. By the implicit function theorem, the equilibrium value $r_{H}^{*}$ is strictly increasing in the threshold level of effort $\widetilde{e}$. This implies that, when parameters belong to case 1 , an increase in $\widetilde{e}$ has a positive effect on the proportion of dishonest agents residing in country 1 . This will also, in turn, affect the tax revenues of the country, as we are going to show in section 4.1 .

Analogously, under case 4, where $\widetilde{e} \geq \frac{w_{1}}{\gamma}$, being $G(r)=G_{L}(r)$, cheaters migrate between the two countries, but in country 1 all cheaters always exert low effort as optimal choice independently on the prevailing share $r$. This is due to the fact that the threshold level for which the cheaters would pay the higher tax rate if audited is so high that it has no relevance in their optimal choice of effort. From (22), by solving equation $G_{L}(r)=0$, an equilibrium for the map (20) is given by ${ }^{11}$

$$
r_{L}^{*}=\frac{w_{1}+m_{2}-w_{2}\left(1-t_{F}\right)}{m_{1}+m_{2}+t_{L} w_{1}+t_{F} w_{2}}
$$

Equilibrium $r_{L}^{*}$ is meaningful provided that it belongs to the interval $[0,1]$ and that $\widetilde{e} \geq \frac{w_{1}}{\gamma}$. Moreover, it is $G_{L}^{\prime}\left(r_{L}^{*}\right)<0$, which is relevant for understanding the local stability of equilibrium $r_{L}^{*}$, as recalled below. From (24) we immediately obtain that, when the level of salaries and the amount of punishment are equal in the two countries $\left(w_{1}=w_{2}\right.$ and $\left.m_{1}=m_{2}\right)$, then $r_{L}^{*} \in(0,1)$ for all possible values of tax rates $t_{F} \in(0,1), t_{L} \in(0,1)$ and $t_{H} \in\left(t_{L}, 1\right)$. In addition, $r_{L}^{*}$ is increasing in $t_{F}, w_{1}$ and $m_{2}$ and decreasing in $m_{1}, t_{L}$ and $w_{2}$, as intuition suggests. Notice that, since $r_{L}^{*}$ describes the migratory behavior of low-effort dishonest agents, it should not be surprising that the higher tax rate $t_{H}$ and the threshold level of effort $\widetilde{e}$ have no effect on this equilibrium. Notice that, $r_{L}^{*}$, differently from $r_{H}^{*}$, is also independent on the effort inefficiency $\gamma$.

Now let us consider the remaining cases. Under case 2 cheaters migrate between the two countries, but in country 1 cheaters never exert low effort as optimal choice. Under case 3, cheaters migrate between the two countries and exert low, high effort or effort at threshold $\widetilde{e}$ as optimal choice as a function of the share $r$. Under equal punishment and wage levels in the two countries $\left(w_{1}=w_{2}\right.$ and $\left.m_{1}=m_{2}\right)$, the branch $G_{M}(r)$ of (22) is strictly decreasing, so

\footnotetext{
${ }^{11}$ Although equation $G_{L}(r)=0$ has always two real roots, it is possible to show employing (11) and (12) that its second solution is always outside the interval $[0,1]$, so that it is not a meaningful equilibrium of the model.
} 
that if an equilibrium $r_{M}^{*}$ exists, obtained by solving the equation $G_{M}\left(r_{M}^{*}\right)=0$, it is unique; moreover, the equilibrium value $r_{M}^{*}$, similarly to $r_{H}^{*}$, depends on the value of the other parameters and, in particular, is strictly increasing with the threshold level of effort $\widetilde{e}$.

When the wage levels and the punishments in the two countries are not equal, numerical evidence shows that, for the economic meaningful ranges of the parameters of the model, zero or one equilibrium in the interval $(0,1)$ can be obtained. These equilibria are obtained by solving equation $G_{i}\left(r_{i}^{*}\right)=0$, provided that $r_{i}^{*}$ belongs to the interval for which $G_{i}(r)$ is employed with $i \in$ $\{L, M, H\}$, according to the piecewise definition of $G(r)$ in $(22) .{ }^{12}$

By assumptions (11) and (12), and from the previous discussion, we can now apply Proposition 1 to equilibria $r_{L}^{*}, r_{M}^{*}$ and $r_{H}^{*}$ so that, whenever one of them is feasible, it is locally asymptotically stable, provided that the non-overshooting condition in (21) holds. ${ }^{13}$ In other words, even if wage levels and punishments were equal in the two countries, a fraction of cheaters would always be present in both countries. Depending on the established effort level $\widetilde{e}$, the model can generate equilibria where cheaters in country 1 provide any type of effort. In addition, in our model there may be configurations where migration will lead all cheaters to live in one country in the long run (either $r^{*}=0$ or $r^{*}=1$ ).

A full characterization of all equilibria is beyond the scope of this paper, but we will consider below the most interesting cases by numerical analysis. In the numerical simulations, we borrow from Bischi et al. (2003a,b) and Bischi et al. (2009) the following functional form for the switching function $M(G(r))$ to be employed in (20):

$$
M(G(r))=\frac{2}{\pi} \arctan \left(\frac{\pi}{2} \lambda G(r)\right)
$$

where $\lambda=M^{\prime}(0)>0$ is a parameter that model the intensity of choice, i.e. in our context the willingness to migrate to a different country for chasing utility differential $G(r)$ in (22). ${ }^{14} \lambda$ can be interpreted as a measure of social integration between the two countries (that may or may not belong to a federal union) or an inverse measure of the costs of migration.

Let us start our discussion with an example with the most interesting scenario, where all three branches of $G(r)$ are employed. This example, although numerical, provides a general description of the typical dynamics of the model. For this purpose, consider the following set of parameters

$$
w_{1}=w_{2}=1.5 ; m_{1}=m_{2}=0.4 ; t_{L}=25 \% ; t_{H}=50 \% ; t_{F}=40 \% ; \gamma=1
$$

\footnotetext{
${ }^{12} \mathrm{~A}$ virtual fixed point is a point that satisfies an equilibrium condition of the form $G_{i}\left(r_{i}^{*}\right)=$ $0, i \in\{L, M, H\}$, but it is ruled out by the piecewise definition of the function $G(r)$ in $(22)$. For instance, a root $r^{*} \in(0,1)$ of equation $G_{H}\left(r^{*}\right)=0$ with $\widetilde{e} \geq \frac{w_{1}}{\gamma}$ is a virtual fixed point.

${ }^{13}$ Note that analytically this holds when $w_{1}=w_{2}$ and $m_{1} \stackrel{\gamma}{=} m_{2}$, although numerical evidence suggests that it is also the case under the general case with $w_{1} \neq w_{2}$ or $m_{1} \neq m_{2}$.

${ }^{14}$ Notice that $M(G(r))$ in $(25)$ satisfies all the requirements for $M$ previously listed. In any case, it is important to observe that the qualitative properties of the dynamics do not depend on the exact specification of $M(G)$ but on the form of the utility differential $G(r)$ in (22), so that (25) is a useful way to obtain in explicit form a dynamical system that models migratory pressure.
} 
and assume first that in country 1 it is $\widetilde{e}=0.8$. Notice that it is $\bar{r} \approx 0.6087$ and $\overline{\bar{r}} \approx 0.9032$, so case 3 holds. Solving equation $G_{H}\left(r_{H}^{*}\right)=0$, we obtain the root $r_{H}^{*} \approx 0.544297<\bar{r}$, which corresponds to an equilibrium of word of mouth dynamics (20). No other equilibria are present under this parameters constellation. ${ }^{15}$ The stability of $r_{H}^{*}$ only depends on the map $M(G)$. With $(25)$, the non-overshooting condition (21) is satisfied for $\lambda<\bar{\lambda}=4.609$. Figure 1(a) shows the cobweb diagram for this case with $\lambda=1$ and two different trajectories with initial conditions $r_{0}^{A}=0.2$ and $r_{0}^{B}=0.8$ converging to $r_{H}^{*}$. The read dots in the bisector are the two levels $\bar{r}<\overline{\bar{r}}$ in the piecewise definition of map (22). Thus, about $54 \%$ of cheaters establish in country 1 and exert a level of effort above $\widetilde{e}$, whereas the complementary fraction chooses country 2 in the long run. Dynamic adjustment related to migration between the two countries eventually leads to that distribution of cheaters in the two countries.

If the regulator in country 1 decides to increment the threshold effort $\widetilde{e}$ till the level at which $r_{H}^{*}=\bar{r}$ (remember that $r_{H}^{*}$ is increasing in $\widetilde{e}$ whereas $\bar{r}$ is decreasing in $\widetilde{e}$ ) this leads to $r_{H}^{*}$ becoming a virtual fixed point and the new equilibrium of the type $r_{M}^{*}$, shown in Figure $1(\mathrm{~b})$ for $\widetilde{e}=1$, all other parameters equal, where $r_{M}^{*} \approx 0.5623 .{ }^{16}$ Equilibrium $r_{M}^{*}$ is again stable and it involves an higher amount of cheaters in country 1, who decide to exert an effort that is exactly equal to the threshold $\widetilde{e}$.

Further increments of $\widetilde{e}$ leads to condition $r_{M}^{*}=\overline{\bar{r}}$, so that $r_{M}^{*}$ is now a virtual fixed point and the only equilibrium is $r_{L}^{*}$ in $(24)$, which is now independent on $\widetilde{e}$. This case is depicted in Figure $1(\mathrm{c})$, where $\widetilde{e}=1.2$ and $r_{L}^{*} \approx 0.5634$.

Notice that in these examples the increments of $\widetilde{e}$ entail small variations of the equilibrium values of cheaters in country 1 . However, two observations are crucial here. The first one, detailed below, is related to the stability of the different equilibrium share of cheaters. The second one, discussed in Subsection 4.1 , is related to variations of tax revenues in the two countries as a consequence of different levels of the effort threshold $\widetilde{e}$.

Regarding the stability of the equilibrium share of cheaters in country one, our leading example has been obtained under a sufficiently small willingness to migrate $\lambda$. When $\lambda>\bar{\lambda}$, equilibria become unstable through a sequence of period-doubling bifurcations, and for increasing values of $\lambda$, chaotic motion occurs, with persistent oscillations of migration between the two countries, due to an high level of impatience of the agents. This occurrence is depicted in Figures 1(d),(e),(f), which correspond to the cases in Figures 1(a),(b),(c) but with the higher willingness to migrate $\lambda=60$. Now a very small utility differential is enough to induce a cheater to migrate in the country where he is better off; this leads to an erratic fluctuation of the share of cheaters and of the probability to be detected as cheater in the two countries, which changes the overall utility evaluation. Interestingly, migration, by changing the share of cheaters and so

\footnotetext{
${ }^{15}$ Solving equation $G_{M}\left(r_{M}^{*}\right)=0$, one obtains the $\operatorname{root} r_{M}^{*}=0.542648$, and, for $G_{L}\left(r_{L}^{*}\right)=0$, the root $r_{L}^{*}=0.56338$. However, as $r_{M}^{*} \notin(\bar{r}, \overline{\bar{r}})$ and $r_{L}^{*} \notin(\overline{\bar{r}}, 1)$ both $r_{M}^{*}$ and $r_{L}^{*}$ are virtual fixed points for the word of mouth dynamics $(20)$.

${ }^{16}$ With $\widetilde{e}=1$ it is $\bar{r} \approx 0.4348, \overline{\bar{r}} \approx 0.6452$ and $\bar{\lambda}=4.84325$, so the non-overshooting condition (21) is satisfied by equilibrium $r_{M}^{*}$.
} 


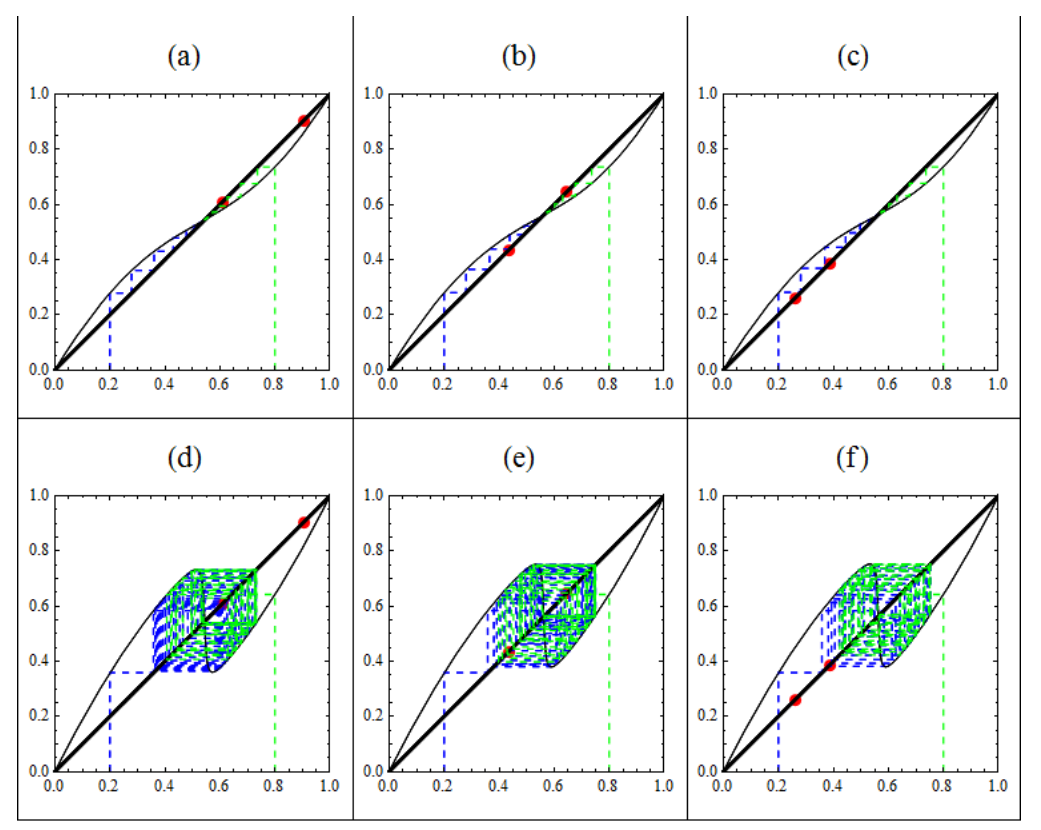

Figure 1: Cobweb plot in the plane $\left(r_{t}, r_{t+1}\right)$ of word of mouth dynamics (20) with (25), showing the transition of equilibria for increasing levels of $\widetilde{e}$, with parameters $w_{1}=w_{2}=1.5 ; m_{1}=m_{2}=0.4 ; t_{L}=25 \% ; t_{H}=50 \% ; t_{F}=40 \%$; $\gamma=1$ (a) $\lambda=1$ and $\widetilde{e}=0.8$ : the generic trajectory converges to $r_{H}^{*}$. (b) $\lambda=1$ and $\widetilde{e}=1$ : the generic trajectory converges to $r_{M}^{*}$. (c) $\lambda=1$ and $\widetilde{e}=1.2$ : the generic trajectory converges to $r_{L}^{*}$. (d) $\lambda=60$ and $\widetilde{e}=0.8$ : chaotic attractor with high and threshold effort. (e) $\lambda=60$ and $\widetilde{e}=1$ : chaotic attractor with high, threshold and low effort (f) $\lambda=60$ and $\widetilde{e}=1.2$ : chaotic attractor with low effort.

the probability to be detected, induces different effort levels of cheaters in country one, i.e. below, at or above the threshold $\widetilde{e}$, so that over time different tax rates are applied to audited cheaters. This can be noticed by inspecting Figure 1(d),(e),(f). In Figure 1(d), migration occurs chaotically, and cheaters always choose either high effort or effort at the threshold $\widetilde{e}$ (the chaotic attractor is all below the point $\overline{\bar{r}}$ ); in the case of Figure 1(e), any level of effort can be exerted by cheaters, whereas, in the case of Figure 1(f), although dynamics is erratic, all the points of the chaotic attractor are above the level $\overline{\bar{r}}$ : cheaters in country 1 always exert a low level of effort in order to pay the lower tax rate $t_{L}$.

A useful way to summarize our leading example is depicted in the bifurcation diagram of Figure 2 as the threshold $\widetilde{e}$ is increased. Figure 2(a) shows the case with low migration propensity ensuring that the various equilibria of the model are locally asymptotically stable. As recalled before, an increase in the threshold $\widetilde{e}$ has a positive effect on $\mathbb{E}\left[U_{1}^{H^{*}}\right]$ and $\mathbb{E}\left[U_{1}^{M^{*}}\right]$ and no effect on $\mathbb{E}\left[U_{1}^{L^{*}}\right]$. This can be clearly seen in Figure 2(a): as $\widetilde{e}$ increases, equilibrium $r_{H}^{*}$ increases 


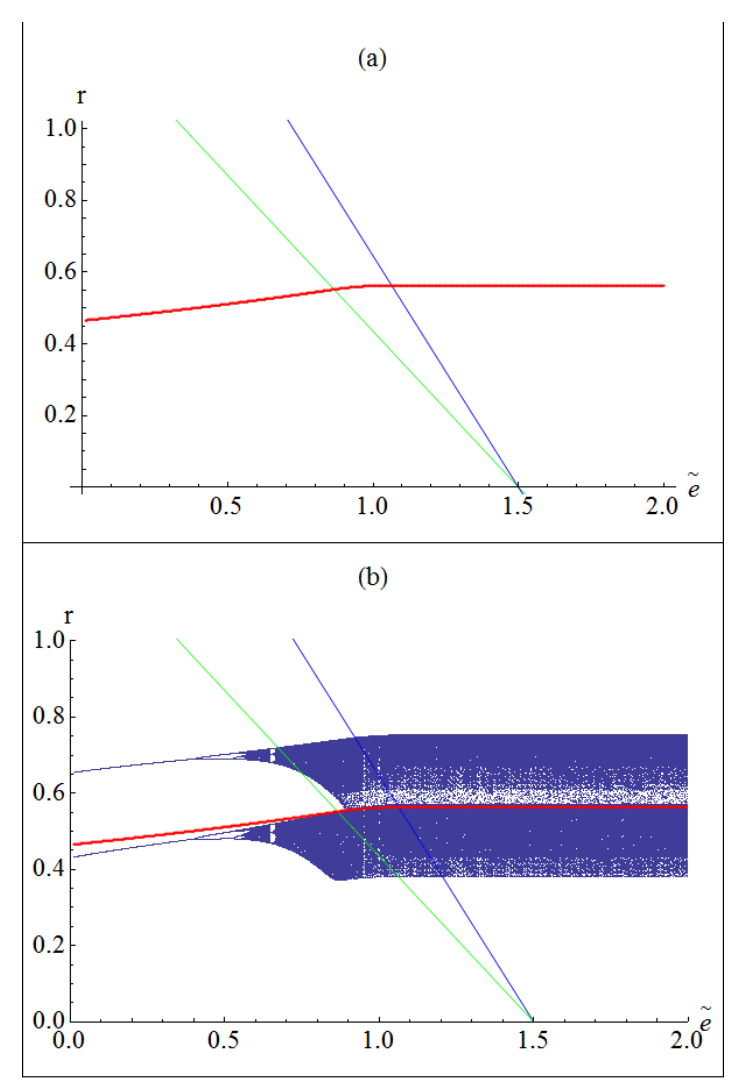

Figure 2: Bifurcation diagram showing the possible long-term values (equilibria, periodic or chaotic orbits) of $r$ as a function of the threshold $\widetilde{e} \in[0,2]$ with parameters as in Figure 1. (a) $\lambda=1$, showing convergence to the equilibrium share of cheaters. (b) $\lambda=60$, chaotic dynamics of the distribution of cheaters in the two countries; the red curve depicts the average level of $r$ along the attractor.

(region I, below the green line, where $G_{H}(r)$ applies); this also occurs for $r_{M}^{*}$ (region II, between the green line and the blue line); clearly, further increments of $\widetilde{e}$ have no influence on $r_{L}^{*}$ (region III, on the right of the blue line). Figure 2(b) depicts the similar case with higher willingness to migrate $(\lambda=60)$; dynamics is chaotic, but on average (see the red curve) the results are analogous to those in Figure 2(a). Also in this case, for different values of $\widetilde{e}$, the trajectories of the system can belong to regions where the definition of the dynamical system is different. In other words, we can observe oscillations of the shares of cheaters in the two countries with the application of different tax rates to audited dishonest agents over time.

Next we address main implications of the choice of the tax system for the expected tax revenues of the two countries. 


\subsection{Effects on tax revenues}

Here we briefly consider the tax revenues to the two countries arising from auditing the whole population of taxpayers. Let us denote by $\alpha$ the proportion of honest taxpayers living in country 1 , so that $1-\alpha$ lives in country 2 . For the sake of simplicity, let us assume that they are not willing to migrate for fiscal purposes. ${ }^{17}$ Country $i$ audits randomly agents from its population and incurs a fixed cost for auditing $k_{i}$.

Net tax revenues in country 2 can be written as follows:

\section{Country 2}

\begin{tabular}{|l|l|l|}
\hline & Compliance & Evasion \\
\hline Audit & $e_{2}^{+} w_{2} t_{F}-k_{2}$ & $e_{2}^{*}\left(w_{2} t_{F}+m_{2}\right)-k_{2}$ \\
\hline No audit & $e_{2}^{+} w_{2} t_{F}$ & 0 \\
\hline
\end{tabular}

where $e_{2}^{+}$and $e_{2}^{*}$ are, respectively, the optimal effort by a representative honest and dishonest agent, defined in Section 2. All in all the net expected tax revenue in country 2 is

$$
\begin{aligned}
T R_{2}= & \underbrace{(1-\alpha)(1-r)\left(e_{2}^{+} w_{2} t_{F}-k_{2}\right)}_{\text {tax revenues from audited honest agents }}+\underbrace{(1-\alpha) r\left(e_{2}^{+} w_{2} t_{F}\right)}_{\text {tax revenues from nonaudited honest agents }}+ \\
& +\underbrace{(1-r)^{2}\left[e_{2}^{*}\left(w_{2} t_{F}+m_{2}\right)-k_{2}\right]}_{\text {tax revenues from audited cheaters }}
\end{aligned}
$$

where we employed the assumption that the probability to audit in country 2 is $p_{2}=1-r$.

In Country 1 the calculation is analogous, but different tax rates are in place and agents choose optimal effort also according to the effort threshold $\widetilde{e}$. The tax revenues from honest and dishonest taxpayers are summoned up in the following tables:

\section{Country 1}

Tax revenues from honest taxpayers:

\begin{tabular}{|l|l|l|}
\hline & $e \leq \widetilde{e}$ & $e>\widetilde{e}$ \\
\hline Audit & $e_{1}^{+} w_{1} t_{L}-k_{1}$ & $e_{1}^{+} w_{1} t_{H}-\widetilde{e} w_{1}\left(t_{H}-t_{L}\right)-k_{1}$ \\
\hline No audit & $e_{1}^{+} w_{1} t_{L}$ & $e_{1}^{+} w_{1} t_{H}-\widetilde{e} w_{1}\left(t_{H}-t_{L}\right)$ \\
\hline
\end{tabular}

Tax revenues from dishonest taxpayers:

\begin{tabular}{|l|l|l|}
\hline & $e \leq \widetilde{e}$ & $e>\widetilde{e}$ \\
\hline Audit & $e_{1}^{*}\left(w_{1} t_{L}+m_{1}\right)-k_{1}$ & $e_{1}^{*}\left(w_{1} t_{H}+m_{1}\right)-\widetilde{e} w_{1}\left(t_{H}-t_{L}\right)-k_{1}$ \\
\hline No audit & 0 & 0 \\
\hline
\end{tabular}

\footnotetext{
${ }^{17}$ Notice that we are assuming also that honest taxpayers constitute a unit mass of agents as the mass of dishonest agents. Thus, we could introduce another parameter for the proportion of dishonest taxpayers in the whole population. However, since it does not affect qualitatively the main results, we leave the setting as described.
} 
from which we can calculate the tax revenues from honest taxpayers ${ }^{18}$

$T R_{1}^{H}=\left\{\begin{array}{l}\alpha r\left(e_{L}^{+} w_{1} t_{L}-k_{1}\right)+\alpha(1-r)\left(e_{L}^{+} w_{1} t_{L}\right) \text { if effort below or at } \widetilde{e} \\ \alpha r\left(e_{H}^{+} w_{1} t_{H}-\widetilde{e} w_{1}\left(t_{H}-t_{L}\right)-k_{1}\right)+\alpha(1-r)\left(e_{H}^{+} w_{1} t_{H}-\widetilde{e} w_{1}\left(t_{H}-t_{L}\right)\right) \text { if effort above } \widetilde{e}\end{array}\right.$

and from dishonest taxpayers

$$
T R_{1}^{D}=\left\{\begin{array}{l}
r^{2}\left(e_{L}^{*} w_{1} t_{L}+e_{L}^{*} m_{1}-k_{1}\right) \text { if effort below or at } \widetilde{e} \\
r^{2}\left(e_{H}^{*} w_{1} t_{H}+e_{H}^{*} m_{1}-\widetilde{e} w_{1}\left(t_{H}-t_{L}\right)-k_{1}\right) \text { if effort above } \widetilde{e}
\end{array}\right.
$$

from which it is

$$
T R_{1}=T R_{1}^{H}+T R_{1}^{D}
$$

Let us reconsider the numerical example described above and assume that $k_{1}=k_{2}=0.5$ and $\alpha=0.5$ (equal distribution of honest agents in the two countries). As $T R_{1}$ and $T R_{2}$ ultimately depend on the share $r$ of cheaters in the two countries, it is interesting to depict the tax revenues in the two countries as a function of the share $r$.

When migration propensity is low (e.g. $\lambda=1$ ), we have shown that in the long run the share of cheaters in the two countries converges to a stable equilibrium. This implies also that the tax revenues in the two countries stabilize to a fixed level for any given $\widetilde{e}$. An increment of $\widetilde{e}$, however, will slightly increase and then reduce tax revenues in country 2, see Figure 3(b). However, changes in $\widetilde{e}$ may have a strong influence on the long-run tax revenues in country 1 , as shown in Figure 3(a): increasing $\widetilde{e}$ initially determines a decrement and then an increment of $T R_{1}$. For sufficiently high levels of $\widetilde{e}$, this threshold level does not have any influence on tax revenues in the two countries. In this specific example, it is also visible a discontinuity in the tax revenues of country 1 , which is induced by the different efforts exerted by agents when they choose it above or below $\widetilde{e}$ (see (13)). The non-monotonic shape of $T R_{1}$ is confirmed by additional simulations that we are not reporting here for expositional reasons. In particular, $T R_{1}$ achieves always a minimum for intermediate levels of $\widetilde{e}$. The discontinuity of $T R_{1}$ depends, on the other hand, on the specific parameters constellation of this example. The intuition behind this result is as follows. When $\widetilde{e}$ is low and the majority of cheaters are in country 2 (low $r$, see Figure $2(\mathrm{a}))$, small increments of this threshold entail that cheaters residing in country 1 exert decreasing optimal effort $e_{H}^{*}$ and that the share of cheaters in country $1, r$, increases. The overall effect is a decrease in tax revenues in country 1 , given the low probability to detect dishonest agents. This tendency changes for larger values of $\widetilde{e}$ as $r$ is substantially increased, so that it is more likely to detect dishonest agents in country 1 and charging them the fee $m_{1}$. When $\widetilde{e}$ is very high, the share $r$ does not depend on the threshold and so also tax revenues become constant. The analysis shows that tax revenues for country 1 are highest when the tax system is closest to a flat rate regime. When $\widetilde{e} \rightarrow 0$

\footnotetext{
${ }^{18} e_{L}^{+}$and $e_{H}^{+}$are the optimal efforts below or above the threshold $\widetilde{e}$, obtained from (13) by setting $m_{1}=0$ and $p_{1}=1$, defined in Section 2 .
} 


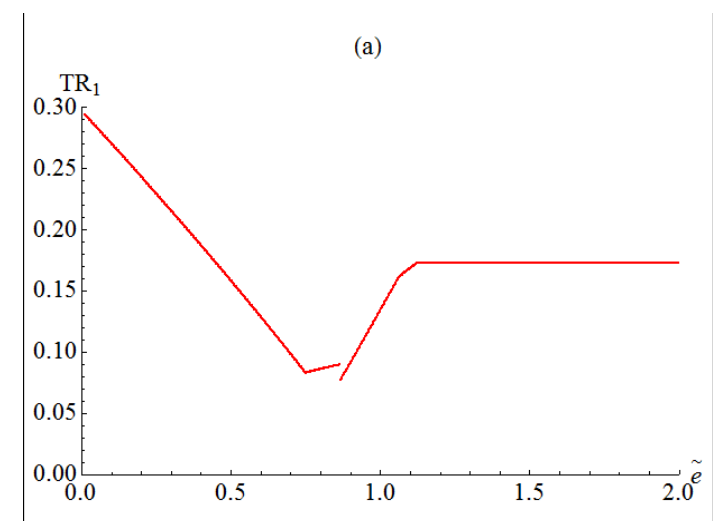

(b)

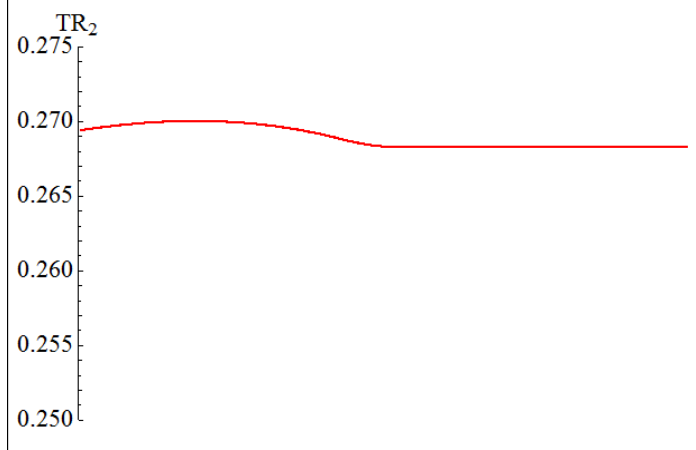

Figure 3: Long-run tax revenues in the two countries as a function of the threshold $\widetilde{e} \in[0,2]$ with parameters as in Figure 1 and $\lambda=1$ (a) tax revenues in country 1 (b) tax revenues in country 2 .

country 1 is imposing a flat rate of $t_{H}$, while when $\widetilde{e} \rightarrow \infty$ the system produces a regime with a flat rate of $t_{L}$. Intermediate values of $\widetilde{e}$, i.e. a progressive tax system, tends to positively influence migration and tax evasion, ultimately, to the detriment of tax revenues.

An analogous exercise with chaotic dynamics for the share of cheaters in country 1 is proposed in Figure $4(\mathrm{a}),(\mathrm{b})$, where $\lambda=60$. Average tax revenues in the two countries are represented by the red curves, showing the same qualitative behavior of the previous case with $\lambda=1$.

\section{Conclusions}

Many features of a tax system, including its degree of progressivity and the strictness of the auditing system, have important effects on the decisions of economic agents. Some individuals may find desirable to migrate to other countries if they expect to experience an improvement of their (post-tax / post-auditing) 


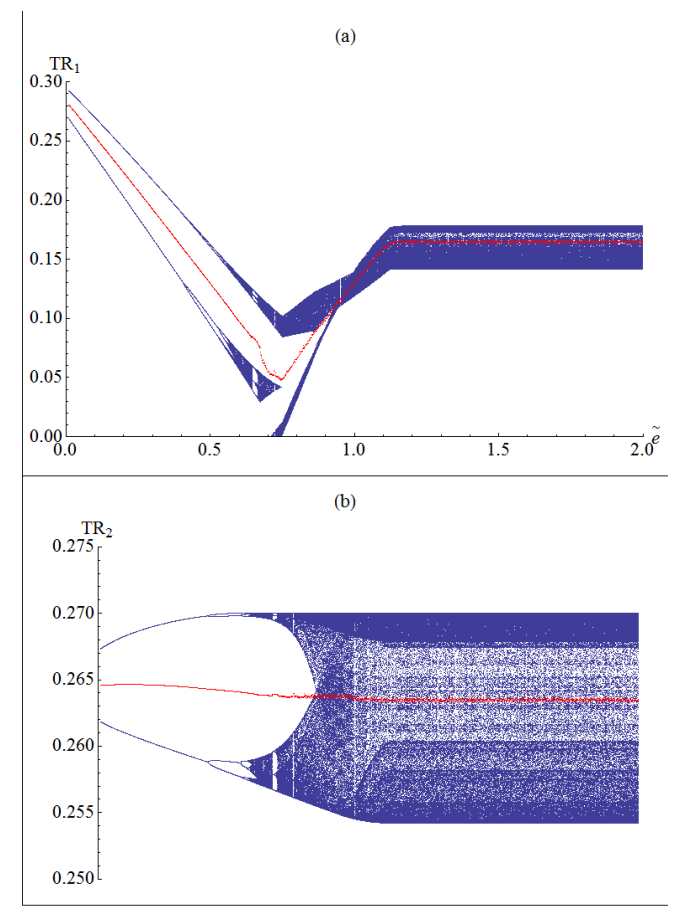

Figure 4: Long-run tax revenues in the two countries as a function of the threshold $\widetilde{e} \in[0,2]$ with parameters as in Figure 1 and $\lambda=60$; the red curve depicts the average level of tax revenues along the chaotic trajectory. (a) tax revenues in country 1 (b) tax revenues in country 2. 
utility. In order to study the way tax competition in an international setting may affect economic behavior and in particular the level of tax evasion in the long run, we studied an evolutionary model in which economic agents decide in each period how much effort to invest in economic activities and whether to migrate abroad to a more favorable taxation system.

We considered a two-country setting and studied an evolutionary model in which the fraction of dishonest taxpayers residing in each country is endogenized and updated according to expected utilities and word of mouth dynamics.

We have shown that various dynamic long term scenarios can be generated. Factors that improve the desirability for a dishonest individual to reside in the country with flat rate tax system (e.g. improvement in the salary differential and/or auditing penalties, reduction of the flat rate) make the system transition from scenarios in which all dishonest individuals migrate to the progressive country to equilibria where dishonest individuals are distributed in both countries. The stability of the interior equilibria may be affected by overshooting. Chaotic cyclical behavior, indeed, may arise if individuals' propensity to migrate is sufficiently high. In addition, we have shown that the particular evolutionary trajectory of tax evasion and migration that a country can experience critically depends on the level of progressivity of a tax system. Specifically, the progressivity of a tax regime influences individuals' choices in terms of effort and migration and this, in turn, has consequences on the ability of a country to generate tax revenues. Our analysis shows that considering a flat rate system may have positive effects on the tax revenues of a country.

\section{References}

Allingham, M.G., Sandmo, A. (1972), "Income tax evasion: a theoretical analysis", Journal of Public Economics, 1(3-4):323-338.

Alm, J., Martinez -Vazquez, J., Torgler, B. (2010), "Developing Alternative Frameworks for Explaining Tax Compliance". Florence, Kentucky: Routledge.

Becker, G.(1968), "Crime and Punishment: An Economic Approach", Journal of Political Economy, 76, 169-217.

Bénabou, R., Tirole, J. (2006), "Incentives and Prosocial Behavior," American Economic Review, 96(5), 1652-1678.

Besley, T., Ghatak, M. (2005), "Competition and incentives with motivated agents", American Economic Review, 95, 616-636.

Bischi G.I., Dawid, H., Kopel, M. (2003a), "Spillover Effects and the Evolution of Firm Clusters". Journal of Economic Behavior and Organization, 50, 47-75.

Bischi G.I., Dawid, H., Kopel, M. (2003b), "Gaining the Competitive Edge Using Internal and External Spillovers: A Dynamic Analysis", Journal of Economic Dynamics and Control, 27, 217-219.

Bischi G.I., Lamantia F. (2012), "Routes to complexity induced by constraints in Cournot oligopoly games with linear reaction functions", Studies in Nonlinear Dynamics $\& 3$ Econometrics, 16 (2).

Bischi G.I., Lamantia F., Radi D. (2015), "An evolutionary Cournot model with limited market knowledge", Journal of Economic Behavior $\mathcal{E}$ Organization, 
$116,219-238$.

Bischi G.I., Lamantia F., Sbragia L. (2009), "Strategic interaction and imitation dynamics in patch differentiated exploitation of fisheries". Ecological Complexity. 6 353-362.

Borjas, G. J. (1999), "The economic analysis of immigration," Handbook of Labor Economics, in: O. Ashenfelter and D. Card (ed.), Handbook of Labor Economics, edition 1, volume 3, chapter 28, pages 1697-1760, Elsevier.

Bucovetsky, S. (2003), "Efficient migration and income tax competition", Journal of Public Economic Theory, 5 (2), 249-278.

Castro, L., Scartascini, C. (2015), "Tax compliance and enforcement in the pampas evidence from a field experiment", Journal of Economic Behavior \&3 Organization , 116, 65-82.

Cellini, R., Lamantia, F. (2015), "Quality Competition in Markets with Regulated Prices and Minimum Quality Standards", Journal of Evolutionary Economics, 25-2, 345-370.

Cerboni Baiardi, L., Lamantia, F., Radi, D. (2015), "Evolutionary competition between boundedly rational behavioral rules in oligopoly games", Chaos, Solitons 85 Fractals, 79, 204-225.

Commendatore, P., Kubin, I., Mossay, P., Sushko, I. (2015), "Dynamic agglomeration patterns in a two-country NEG model with four regions", Chaos, Solitons \&3 Fractals, 79, 2-17.

Cressman, R. (2003), Evolutionary dynamics and extensive form games. The MIT Press, Cambridge.

Cumming, R. G., Martinez-Vasquez, J., McKee, M., Torgler, B. (2009), "Tax morale affects tax compliance: Tax morale affects tax compliance: Evidence from surveys and an artefactual field experiment", Journal of Economic Behavior and Organization, 70, 447-457.

Dawid, H. (1999), "On the dynamics of word of mouth learning with and without anticipations", Annals of Operations Research, 89, 273-295.

De Giovanni, D., Lamantia, F. (2016), "Control delegation, information and beliefs in evolutionary oligopolies", Journal of Evolutionary Economics, 26-5, 1089-1116.

Doerrenberg, P. (2015), "Does the use of tax revenue matter for tax compliance behavior?", Economics Letters, 128, 30-34.

Droste, E., Hommes C., Tuinstra J. (2002), "Endogenous Fluctuations Under Evolutionary Pressure in Cournot Competition", Games and Economic Behavior, 40, 232-269.

Ellison, G., Fudenberg, D. (1995), "Word-of-mouth communication and social learning", Quarterly Journal of Economics CX, 93-125.

Freire-Serén, M.J., Panadés, J. (2013), "Do Higher Tax Rates Encourage/Discourage Tax Compliance?", Modern Economy, 4(12), 809-817.

Frey, B. S. (2003), "Deterrence and tax morale in the European Union", European Review, 11(3), 385-406.

Gangl, K., Hofmann, E., Kirchler, E. (2015), "Tax authorities' interaction with taxpayers: A conception of compliance in social dilemmas by power and trust", New Ideas in Psychology, 37, 13-23. 
Gorodnichenko, Y., Martinez-Vazquez, J., Sabirianova Peter, K. (2009), "Myth and Reality of Flat Tax Reform: Micro Estimates of Tax Evasion Response and Welfare Effects in Russia," Journal of Political Economy, 117(3), 504-554.

Kopel, M., Lamantia, F., Szidarovszky, F. (2014), "Evolutionary Competition in a Mixed Market with Socially Concerned Firms", Journal of Economic Dynamics \& Control, 48, 394-409.

Lamantia, F., Pezzino, M. (2016), "Evolutionary Efficacy of a Pay for Performance Scheme with Motivated Agents", Journal of Economic Behavior and Organization, 125, 107-119.

Luttmer, E.F.P. and Singhal, M., (2014), "Tax morale", Journal of Economic Perspectives, 28, pages 143-168.

Mirrlees, J. A. (1971), "An Exploration in the Theory of Optimum Income Taxation", Review of Economic Studies, 38(2), 175-208.

Mirrlees, J. A. (1982), "Migration and optimal income taxes", Journal of Public Economics, 18(3), 319-341.

Razin, A., Sadka, E., Swagel, P. (2002), "Tax burden and migration: a political economy theory and evidence", Journal of Public Economics 85-2, 167190

Simula, L., Trannoy, A. (2010), "Optimal income tax under the threat of migration by top-income earners", Journal of Public Economics, 94, 163-173.

Tramontana F., Gardini L., Puu T. (2010), "Global Bifurcations in a PiecewiseSmooth Cournot Duopoly Game", Chaos, Solitons and Fractals. 43 15-24.

Yitzhaki, S. (1974), "Income tax evasion: a theoretical analysis", Journal of Public Economics, 3(2), 201-202.

Slemrod, J., Yitzhaki, S. (2002), "Tax avoidance, evasion, and administration," Handbook of Public Economics in: A. J. Auerbach \& M. Feldstein (eds.), Handbook of Public Economics, edition 1, volume 3, chapter 22, pages 14231470, Elsevier.

Weibull, J. (1995), Evolutionary Game Theory, Cambridge, MA: The M.I.T. Press. 